\title{
STABILITY OF ARSENIC DURING SOIL TREATMENT AND STORAGE
}

\author{
CRISTIAN VARGAS ${ }^{a}$,WALDO QUIROZ*a, MANUEL BRAVO ${ }^{a}$, ALEXANDER NEAMAN \\ ${ }^{a}$ Instituto de Química, Pontificia Universidad Católica de Valparaíso, Avenida Parque Sur 330 Curauma, Valparaíso, Chile. \\ ${ }^{b}$ Escuela de Agronomía, Pontificia Universidad Católica de Valparaíso, Quillota, Chile.
}

\begin{abstract}
There are many studies in the area of identifying and measuring arsenic (As) and its species in soil samples. However, stability of total As, As(V) and As(III) during sample drying and storage has received little attention. The present study evaluates the stability of total As, As(V) and As(III) in four soils with differing agricultural uses and physicochemical properties. Moisture elimination conditions were evaluated, i.e. lyophilization for 1 day vs. drying at $50^{\circ} \mathrm{C}$ for 3 days, along with different storage conditions, i.e. room temperature for 2 days vs. $-20^{\circ} \mathrm{C}$ for 2 days. The results show that the recovered levels of native $\mathrm{As}(\mathrm{V})$ and $\mathrm{As}(\mathrm{III})$ are highest using lyophilization and storage at $-20^{\circ} \mathrm{C}$. Under these optimal conditions, total As content and the levels of As(V) and As(III) remain stable up to 10 days of storage with an error of $\pm 20 \%$.
\end{abstract}

Keywords: arsenic; speciation; soil; storage; stability.

\section{INTRODUCTION}

Arsenic (As) is one of the most commonly studies metalloids in environmental sciences due its known toxicity and its association with several types of cancer [1,2]. The abundance of As in our planet is in the order of 1.5 to $3 \mathrm{mg} \mathrm{kg}^{-1}$ [3]. In soils, As is found mainly in its inorganic forms. In wellaerated soils, the predominant chemical form is $\mathrm{As}(\mathrm{V})$ in the form of arsenates, and in poorly-aerated soils, the predominant chemical form is As(III), in the form of arsenite [3].

It is known that the toxicity and mobility of As depends of its chemical forms; for example, $\mathrm{As}(\mathrm{III})$ is more toxic than $\mathrm{As}(\mathrm{V})$ [4]. As a result there have been many publications regarding methods for As speciation. Development in this field has therefore focused on the extraction stages in terms of performance and species stability, chromatographic separation using mainly liquid chromatography and finally, detection systems [5], leaving aside studies of the stability of these inorganic species during the drying and storage steps.

Though some conclusions have been drawn regarding storage conditions for determining As in liquid samples, such as natural water and urine[6], for the case of solid samples, reports are very rare, contradictory and as such there are no standard storage practices for the process of determining $\mathrm{As}(\mathrm{V})$ and $\mathrm{As}(\mathrm{III})$. In the few studies in existence the focus is placed on solid biological matrices [7], and of all the studies regarding the stability of $\mathrm{As}(\mathrm{V})$ and $\mathrm{As}(\mathrm{III})$ during solid sample storage, surprisingly, there are just one article that consider soil samples. In this study performed by Huang and Ilgen[8] $\mathrm{MeOH}$-water was used as extracting agent clearly focused on the solubilization organic As species more than inorganic ones. This study recommends conducting As speciation in fresh and wet soil samples to avoid As species transformation.

Considering these state of art, we believe that As speciation in soil requires more stability studies on storage and drying steps, with special attention on extracting agents focused on the solubilization of inorganic $\mathrm{As}(\mathrm{V})$ and $\mathrm{As}(\mathrm{III})$ species. The main aim of this study is, therefore, to evaluate the stability of $\mathrm{As}(\mathrm{V})$ and $\mathrm{As}(\mathrm{III})$ during soil drying and storage.

\section{EXPERIMENTAL}

\section{Apparatus}

The chromatographic separation of As species was performed using a Jasco (Easton, MD 21601 USA) HPLC system PU2089S Plus model equipped with quaternary pumps, degassers, an auto sampler, an injector with a $100 \mu \mathrm{L}$ loop and a short Hamilton PRP-X100 column $(100 \mathrm{~mm} \times 4.1 \mathrm{~mm})$ with small particle size $(5 \mu \mathrm{m})$.

Hydride Generation-Atomic Fluorescence Spectrometry (HG-AFS), a PSA Analytical Millennium model (10055) atomic fluorescence spectrometer (Ornpington, Kent, UK) was used as the HPLC detector system. This instrument has a continuous flow system for hydride generation coupled to a commercial dryer membrane (Perma Pure product, dryer model MD-11012 FP) attached to the fluorescence spectrometer. Stibine was purged with an atomization flame under an argon flow. Hydrogen, produced in the hydride generation reaction between $\mathrm{NaBH}_{4}$ and $\mathrm{HCl}$, was used to sustain the flame. In addition, a supplementary $\mathrm{H}_{2}$ flow was injected in order to maintain a stable argon/hydrogen diffusion flame.

The instrument was equipped with an As boosted-discharge hollow cathode lamp (BDHCL) from Photron PTY Ltd. (Victoria, Australia), operating at 35.9 $\mathrm{mA}$. Data acquisition was performed using a microcomputer with Avalon software from PS Analytical.

\section{Standard solutions and reagents}

The purities of all chemicals and reagents used in this study were of analytical-grade or higher. Deionised water $\left(18.2 \mathrm{M} \Omega \mathrm{cm}^{-1}\right)$ was obtained using a Nanopure system (Barnstead, Dubuque, IA, USA). Glass and polyethylene containers were cleaned by soaking for 1 day in $10 \% \mathrm{v} / \mathrm{v}$ nitric acid (analytical grade) and were then rinsed several times with deionised water before use. Nitric acid $(65 \% \mathrm{w} / \mathrm{v}$, super pure grade), $\mathrm{HCl}(37 \% \mathrm{w} / \mathrm{v}$, p.a. grade) and hydrogen peroxide $\left(\mathrm{H}_{2} \mathrm{O}_{2}\right)(30 \%)$ were used for digestion, and were purchased from Merck in Darmstadt, Germany.

The mobile phases were prepared daily via solubilization of $\left(\mathrm{NH}_{4}\right)_{2} \mathrm{HPO}_{4}$ and $\mathrm{NH}_{4} \mathrm{H}_{2} \mathrm{PO}_{4}$ (Merck p.a.) with purified water.

The sodium borohydride solution $(0.75 \% \mathrm{w} / \mathrm{v})$ was prepared by dissolving solid $\mathrm{NaBH}_{4}$ (Merck p.a.) with $\mathrm{NaOH}$ solution at $0.4 \%$ w/v (Merck p.a.). This solution was prepared daily just before use, or was stored in a refrigerator at $4^{\circ} \mathrm{C}$ for a maximum of 2 days. In order to reduce the $\mathrm{As}(\mathrm{V})$ present in samples, a solution of $\mathrm{Kl}$ at $1.5 \% \mathrm{w} / \mathrm{v}$ dissolved in ascorbic acid at $0.6 \% \mathrm{w} / \mathrm{v}$ was used (both reagents were obtained from Merck p.a.).

Standard solutions of $1000 \mathrm{mg} \mathrm{L}^{-1}$ of $\mathrm{As}(\mathrm{V})$ and $\mathrm{As}(\mathrm{III})$ were prepared using their respective reactive, $\mathrm{As}_{2} \mathrm{O}_{3}\left(99.5 \%\right.$ Merck) and $\mathrm{NaAsO}_{2}(98 \%$ Merck). Lower concentration working solutions were prepared daily by appropriate dilution with deionized water. High purity reagents were used to digest the different solid samples.

\section{Sample collection and characterization}

For this study, four samples of agricultural soils were used; three of the samples were from soils used to grow garlic, artichoke and carrot, respectively, and the fourth soil was under fallow.

The soil samples were collected in the Aconcagua river basin in central Chile. Sampling points were chosen based on prior knowledge of the spatial distribution of the effects of copper mining on the agricultural soils in the Aconcagua river basin [9] using an expert judgment sampling approach [10],[11]. It is known that As is generally present in significant quantities in copper ores [12]. The first site was in Catemu, near the Chagres copper smelter, which has been in operation since 1927 and has emitted significant loads of As into the atmosphere, especially before 1991, when mitigation measures were put into place at the smelter [13]. The second site was in El Melón, where high concentrations of As resulted from the destruction of a tailing dam during an earthquake in 1965 [14]. These two areas are representative of long-term contamination, and As is likely to be found in stable forms in these soils.

According to the sampling sites Chagres samples are codified as " $\mathrm{CH}$ " and El Melón sample as "MN".

For general physic-chemical characterization of the soils, the samples were dried at $40{ }^{\circ} \mathrm{C}$ and sieved through a $2-\mathrm{mm}$ mesh. The organic matter content was determined by wet combustion with sodium dichromate and 
sulfuric acid without heat application (Sadzawka et al., 2006). The texture was determined using a simplified hydrometer method (Sheldrick and Wang, 1993). The electrical conductivity was determined in the saturated paste extracts (Sadzawka et al., 2006)

For As stability analyses, the samples were sieved through meshes sized 2 $\mathrm{mm}$ and $200 \mu \mathrm{m}$. The sieved fractions were then stored at $-20^{\circ} \mathrm{C}$ until analysis. Storage time was always 2 days, except for stability studies, where storage time was extended until 10 days.

\section{Determination of total As, As(V) and As(III) in soil samples}

In order to determine the concentration of $\mathrm{As}(\mathrm{V})$ and $\mathrm{As}(\mathrm{III})$ in the soils, solid-liquid extractions were first performed with $\mathrm{HCl}$ followed by mechanical stirring, based on a protocol published previously by Giacomino et al. [15]. Approximately $0.3 \mathrm{~g}$ of soil was weighed in $50 \mathrm{~mL}$ polycarbonate centrifuge tubes, to which $10 \mathrm{~mL}$ of concentrated $\mathrm{HCl}$ was added. The tube was then closed and covered with aluminium foil. The suspension was shaken at a velocity of $350 \mathrm{rpm}$ for 1.5 hours at room temperature. The samples were then centrifuged for 5 minutes at $3000 \mathrm{rpm}$. Finally, the supernatant was filtered through a 0.45 $\mu \mathrm{m}$ membrane and completed to $100 \mathrm{~mL}$ for subsequent analysis.

For the total extractable As content analysis, approximately $0.1 \mathrm{~g}$ of sample was weighed and the protocol described above was applied. However, instead of filtering the samples, $10 \mathrm{~mL}$ of $\mathrm{Kl}$ at $15 \% \mathrm{w} / \mathrm{v}$ in ascorbic acid at $3 \% \mathrm{w} / \mathrm{v}$ was added to the samples, which were then gauged to $100 \mathrm{~mL}$. The samples were then covered with aluminium foil and left to stand for approximately 1 hour before analysis. The experimental conditions for separation and detection of arsenic compounds are shown in table 1.

Considering that no soils with certified $\mathrm{As}(\mathrm{V})$ and $\mathrm{As}(\mathrm{III})$ concentrations are available, recovery was always determined by the following expression.

$$
\% \text { recovery }=\frac{A s_{\text {determined }}}{A s_{\text {wet }}}
$$

Where $\mathrm{As}_{\text {wet }}$ represents total $\mathrm{As}$ or $\mathrm{As}(\mathrm{V})$ or $\mathrm{As}(\mathrm{III})$ concentrations determined before storage and drying. On the other hand, $\mathrm{As}_{\text {determined }}$ represents total $\mathrm{As}$ or $\mathrm{As}(\mathrm{V})$ or $\mathrm{As}(\mathrm{III})$ concentrations determined during drying and storage experiments.

Table 1. Summary of conditions for HPLC coupled to HG-AFS detection system.

\begin{tabular}{|c|c|}
\hline \multicolumn{2}{|c|}{ HPLC } \\
\hline Column & $\begin{array}{l}\text { Hamilton PRP-X-100 }(100 \mathrm{x} \\
4.1 \mathrm{~mm} \text { id, particle size } 5 \mu \mathrm{m})\end{array}$ \\
\hline Mobile phases & $\begin{array}{c}\text { First mobile phases: } \\
\mathrm{NaH}_{2} \mathrm{PO}_{4} / \mathrm{Na}_{2} \mathrm{HPO}_{4}, 2 \mathrm{mM} \text { pH } 5.5 . \\
\mathrm{Second} \mathrm{mobile} \mathrm{phase:} \\
\mathrm{NaH}_{2} \mathrm{PO}_{4} / \mathrm{Na}_{2} \mathrm{HPO}_{4}, 30 \mathrm{mM} \text { pH } \\
\text { 8.0. }\end{array}$ \\
\hline Gradient elution program (min) & $\begin{array}{c}\text { 0.0-2.0: First mobile phase }(100 \%) \\
\text { 2.0-4.0: Second mobile phase } \\
(100 \%) \\
\text { 4.0-10.0: First mobile phase } \\
(100 \%)\end{array}$ \\
\hline Flow rate $\left(\mathrm{mL} \mathrm{min}^{-1}\right)$ & 1.5 \\
\hline Injection volume $(\boldsymbol{\mu L})$ & 100 \\
\hline \multicolumn{2}{|c|}{ HG-AFS } \\
\hline $\mathrm{HCl}$ & $1.5 \mathrm{~mol} \mathrm{~L}^{-1}\left(9 \mathrm{~mL} \mathrm{~min}^{-1}\right)$ \\
\hline $\mathrm{NaBH}_{4}$ & $\begin{array}{c}1.5 \% \mathrm{w} / \mathrm{v} \text { (in } 0.4 \% \mathrm{w} / \mathrm{v} \mathrm{NaOH} \\
0.35 \mathrm{~mL} \mathrm{~min}^{-1} \text { ) }\end{array}$ \\
\hline Primary argon flow $\left(\mathrm{mL} \mathrm{min}{ }^{-1}\right)$ & 300 \\
\hline Secondary argon flow $\left(\mathrm{mL} \mathrm{min}^{-1}\right)$ & 20 \\
\hline Hydrogen flow (auxiliary) $\left(\mathrm{mL} \mathrm{min}{ }^{-1}\right)$ & 60 \\
\hline
\end{tabular}

\section{Data analysis}

The statistical significance (screening) of variables affecting As stability was carried out using a two-level full factorial design, $2^{2}$, with a confidence interval of $95 \%$. All chemometric calculations were performed using Statgraphics Centurion XV for Windows (Statistical Graphics Corp.).

\section{RESULTS AND DISCUSSION}

\section{Statistics screening for soil storage and drying}

For the purposes of this part of the study, stability was made up of two factors, storage temperature and post-storage drying conditions. The screening was carried out using a two-level full factorial design, $2^{2}$, with a confidence interval of $95 \%$. The experimental domain of the variables in question is shown in table 2 .

Table 2. Coded and natural variables for the screening study.

\begin{tabular}{|c|c|c|c|}
\hline \multirow{2}{*}{$\begin{array}{l}\text { Experimental } \\
\text { factors }\end{array}$} & \multirow{2}{*}{$\begin{array}{c}\text { Coded } \\
\text { variables }\end{array}$} & \multicolumn{2}{|c|}{ Levels } \\
\hline & & -1 & +1 \\
\hline Storage* & A & $-20^{\circ} \mathrm{C}$ & Room temperature \\
\hline Drying & B & $\begin{array}{l}\text { Lyophilization for } \\
\qquad 1 \text { day }\end{array}$ & $50^{\circ} \mathrm{C}$ for 3 days \\
\hline
\end{tabular}

* At this stage, storage time was 2 days.

This study included soils of different nature and origin. Their chemical and physical parameters were determined by routine methods[10, 16], as well as the levels of total As, As(V) and As(III) under initial conditions prior to storage and drying. As can be seen (table 3 ) total As is composed quantitatively by the sum of inorganic $\mathrm{As}(\mathrm{V})$ and $\mathrm{As}(\mathrm{III})$ species for $\mathrm{CH} 02$ and $\mathrm{CH} 10$. Meanwhile for $\mathrm{CH} 08$ and MN21 soils, more than $70 \%$ of total As are inorganic $\mathrm{As}(\mathrm{V})+\mathrm{As}(\mathrm{III})$ species where the difference can be explained by the presence of soluble organic species, such as arsenobetaine, which do not generate arsenic hydrides. Both of soils also have a higher content of organic matter, which is consistent with this explanation.

In the factorial design analysis, the presence of repetitions can be used to estimate the experimental to verify which factors and interactions are statistically significant. In this study the effects of the storage and drying parameters for the 4 soils were studied in triplicate, followed for the concentration determination of As(V), As(III) and total As in each evaluation (table 4).

As can be seen, the drying and storage present a significant negative effect for $\mathrm{As}(\mathrm{III})$ and for $\mathrm{As}(\mathrm{V})$; while, for total As no statistically significant effects were observed. This means that drying stage at $50^{\circ} \mathrm{C}$ and storage at room temperature could affect negatively the distribution of the arsenic species, but not the total As content, suggesting that conversion of species is possible under these conditions, but no loss of total As concentration could occur during such drying and storage. Interestingly, a significant interaction is found for the major of part of the analyzed soils, suggesting a synergistic action of both factors on arsenic species stability.. Therefore, the optimal drying and storage conditions were reached drying under lyophilization and storage at $-20{ }^{\circ} \mathrm{C}$, because the increase in storage temperature leads to a loss of As(III) in 3 of the 4 soils. The same occurs during drying at $50^{\circ} \mathrm{C}$, in comparison to lyophilization. This is in agreement with the findings of Mandal et al. (2002), who state that arsenite $\left(\mathrm{H}_{3} \mathrm{AsO}_{3}\right)$ can transform into arsenate $\left(\mathrm{H}_{3} \mathrm{AsO}_{4}\right)$ in a soil matrix in an oxidant environment and at high temperatures [3].

For the case of $\mathrm{As}(\mathrm{V})$, the optimal drying and storage conditions were the same as those for $\mathrm{As}(\mathrm{III})$, i.e. lyophilization and storage conditions at $-20^{\circ} \mathrm{C}$. As seen in table 4, during drying at $50^{\circ} \mathrm{C}$ and storage at room temperature, a negative effect on the recovery of $\mathrm{As}(\mathrm{V})$ in 3 of the 4 soils is observed.

It is interesting to note that for the case of the variation of total As, it is clearly seen in table 4 that the differences in storage and drying conditions are generally not significant. This would mean that there may be inter-conversions between $\mathrm{As}(\mathrm{V})$ and $\mathrm{As}(\mathrm{III})$, the total As content in the sample does not vary.

\section{Stability as a function of time}

Once the optimal conditions were established (lyophilization and $-20^{\circ} \mathrm{C}$ storage), the effect of longer storage time was studied. The influence of storage time up to 10 days on $\mathrm{As}(\mathrm{V}), \mathrm{As}(\mathrm{III})$ and total As content was determined. The recovery percentages of native $\mathrm{As}(\mathrm{V})$ and $\mathrm{As}(\mathrm{III})$ are summarized in Figure 1. 
Table 3. Physiochemical properties of the 4 soils used in the study. Total As, $\mathrm{As}(\mathrm{V})$ and $\mathrm{As}(\mathrm{III})$ concentrations were determined for wet soils before drying and storage steps.

\begin{tabular}{|c|c|c|c|c|c|c|c|c|c|}
\hline $\begin{array}{c}\text { Soil } \\
\text { Crop }\end{array}$ & $\begin{array}{c}\text { EC } \\
\left(\mathrm{dS} \mathrm{m} \mathrm{m}^{-1}\right.\end{array}$ & $\begin{array}{c}\text { Organic matter } \\
(\%)\end{array}$ & Texture & $\begin{array}{c}\text { Sand } \\
(\%)\end{array}$ & $\begin{array}{c}\text { Clay } \\
(\%)\end{array}$ & $\begin{array}{c}\text { Silt } \\
(\%)\end{array}$ & $\begin{array}{c}\text { Total As } \\
\mathrm{mg} \mathrm{kg}^{-1}\end{array}$ & $\begin{array}{c}\text { As(V) } \\
\mathrm{mg} \mathrm{kg}^{-1}\end{array}$ & $\begin{array}{c}\text { As(III) } \\
\mathrm{mg} \mathrm{kg}^{-1}\end{array}$ \\
\hline $\begin{array}{c}\text { CH02 } \\
\text { Garlic }\end{array}$ & 1.34 & 2.00 & Clay loam & 26 & 28 & 46 & $23 \pm 2$ & $21 \pm 1$ & $1.5 \pm 0.1$ \\
\hline $\begin{array}{c}\text { CH08 } \\
\text { Artichoke }\end{array}$ & 1.03 & 3.90 & Loam & 28 & 22 & 50 & $29 \pm 4$ & $20 \pm 1$ & $2.2 \pm 0.1$ \\
\hline CH10 Carrot & 1.78 & 1.72 & Loamy sand & 75 & 3 & 22 & $26 \pm 3$ & $20 \pm 1$ & $4.3 \pm 0.2$ \\
\hline $\begin{array}{c}\text { MN21 } \\
\text { Fallow }\end{array}$ & 1.08 & 5.71 & Loam & 44 & 21 & 35 & $8 \pm 1$ & $5.0 \pm 0.2$ & $1.4 \pm 0.1$ \\
\hline
\end{tabular}

EC: Electrical conductivity; CH: corresponds to samples near "Chagres" location; MN: correspond to sample near "El Melon" location.

Table 4. Statistical effects ${ }^{\mathrm{a}}$ of the storage and drying conditions over the variation in native concentrations of As(V), As(III) and total As for studied soils.

\begin{tabular}{|c|c|c|c|c|}
\hline \multicolumn{5}{|c|}{ As (III) } \\
\hline Soil $\rightarrow$ & $\mathrm{CH} 02$ & $\mathrm{CH} 08$ & $\mathrm{CH} 10$ & MN21 \\
\hline A) Drying & $-13.7(7.3)$ & $-29.2(11.9)$ & $-50.6(9.5)$ & $-43.0(7.1)$ \\
\hline B) Storage & $-23.8(7.3)$ & N.S. ${ }^{b}$ & $-11.7(9.5)$ & $-27.2(7.1)$ \\
\hline A-B Interaction & $-22.4(7.3)$ & N.S. & $14.9(9.5)$ & $29.5(7.1)$ \\
\hline \multicolumn{5}{|c|}{ As (V) } \\
\hline & $\mathrm{CH} 02$ & $\mathrm{CH} 08$ & $\mathrm{CH} 10$ & MN21 \\
\hline A) Drying & $-9.6(6.7)$ & N.S. & N.S. & $-12.7(7)$ \\
\hline B) Storage & $-9.7(6.7)$ & $-4.0(3.4)$ & N.S. & N.S. \\
\hline A-B Interaction & $-7.9(6.7)$ & N.S. & $-12.1(7.3)$ & N.S. \\
\hline \multicolumn{5}{|c|}{ As Total } \\
\hline & $\mathrm{CH} 02$ & $\mathrm{CH} 08$ & $\mathrm{CH} 10$ & MN21 \\
\hline A) Drying & N.S. & N.S. & N.S. & N.S. \\
\hline B) Storage & N.S. & N.S. & N.S. & N.S. \\
\hline A-B Interaction & $10.4(3.5)$ & $10.5(6.4)$ & $8.4(3.7)$ & N.S. \\
\hline
\end{tabular}

a: The effects are presented as a global effects and their confidence limit in parenthesis. B: No significant (p-value $>0.05$ )
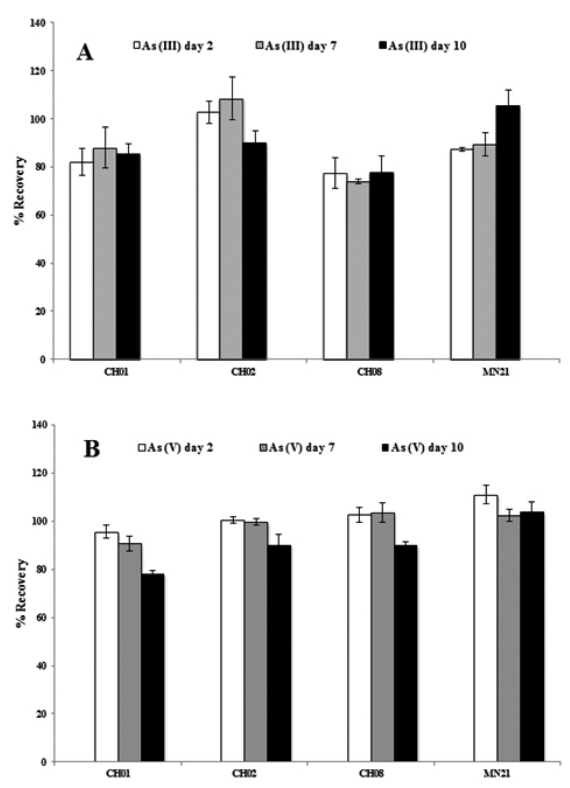

Figure 1. Recovery study of native content of As(III) (A) and As(V) (B) in soils dried by lyophilization and stored at $-20^{\circ} \mathrm{C}$, as a function of storage time. There were no significant differences between the storage times with respect to recovery percentages.
As seen in Figure 1, under optimal drying and storage conditions the variation in $\mathrm{As}(\mathrm{III})$ and $\mathrm{As}(\mathrm{V})$ recovery percentage shows no significant differences, and remains within the error margin of $\pm 20 \%$, without any specific tendency. Considering the natural heterogeneity of soil samples and analytical reproducibility at trace and ultra-trace concentration levels, we believe that $20 \%$ is suitable for analytical purposes and this demonstrates the robustness of the sample treatment for both species, showing high stability even after 10 days.

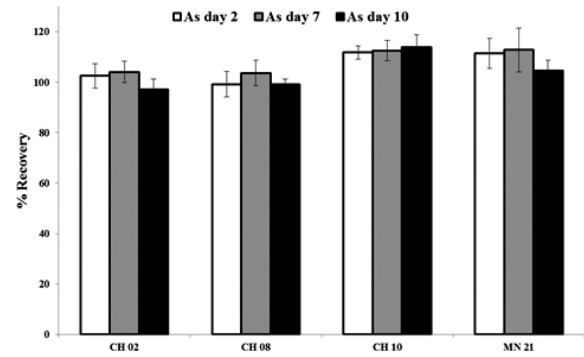

Figure 2. Recovery study of native total As content in soils dried by lyophilization and stored at $-20^{\circ} \mathrm{C}$, as a function of storage time. There were no significant differences between the storage times with respect to recovery percentages.

The variation in total As was also studied as a function of storage time for the 4 soils under optimal drying and storage conditions. As with the case of the stability of $\mathrm{As}(\mathrm{III})$ and $\mathrm{As}(\mathrm{V})$,(Figure 2) show that total As content also presents 
good levels of stability. The total As content remains statistically constant for the 4 soils within a margin of error of $\pm 10 \%$, showing no significant trend up to 10 days of storage.

\section{CONCLUSIONS}

This is the first systematic study in the literature on the stability of As(III), $\mathrm{As}(\mathrm{V})$ and total As content during the process of soil drying and storage. The evidence allows the following conclusions:

The storage and drying process significantly affects $\mathrm{As}(\mathrm{V})$ and $\mathrm{As}(\mathrm{III})$ content in the soils. Storage conditions at $-20^{\circ} \mathrm{C}$ and drying by lyophilization are the most adequate for minimizing losses of both these species during the process. However, the type of drying and storage method does not alter total As content.

With regard to storage time under optimal conditions of $-20^{\circ} \mathrm{C}$ and drying by lyophilization, this study shows that these conditions are sufficiently robust to stabilize native $\mathrm{As}(\mathrm{III}), \mathrm{As}(\mathrm{V})$ and total $\mathrm{As}$, at least for 10 days.

Considering the scarcity of studies regarding the effects of the drying and storage of environmental samples on the stability of As and its species, further studies are required to elucidate As stability in other environmental solid samples.

\section{ACKNOWLEDGEMENTS}

This study was punded by the FONDECYT project 1130041.

\section{REFERENCES}

1.- N. Saint-Jacques, L. Parker, P. Brown, T.J. Dummer, Environ. Health Global Access Sci. Sour., 13 (2014).
2.- E. Bustaffa, A. Stoccoro, F. Bianchi, L. Migliore, Arch. Toxicol., 88 (2014) 1043-1067.

3.- B.K. Mandal, K.T. Suzuki, Talanta, 58 (2002) 201-235.

4.- C.K. Jain, I. Ali, Water Research, 34 (2000) 4304-4312.

5.- K.A. Francesconi, D. Kuehnelt, Analyst, 129 (2004) 373-395.

6.- J.L. Gómez Ariza, E. Morales, D. Sánchez-Rodas, I. Giráldez, TrAC Trends Anal. Chem., 19 (2000) 200-209.

7.- L.V. Rajaković, Z.N. Todorović, V.N. Rajaković-Ognjanović, A.E. Onjia, J. Serb. Chem. Soc., 78 (2013) 1461-1479.

8.- J.H. Huang, G. Ilgen, Int. J. Environ. Anal. Chem., 86 (2006) 347-358.

9.- R. Aguilar, C. Hormazábal, H. Gaete, A. Neaman, J. Soil Sci Plant Nutri., 11 (2011) 125-145.

10.- D.L. Sparks, S.S.S.o. America, A.S.o. Agronomy, Methods of Soil Analysis: Part 3, Chemical methods, Soil Science Society of America, 1996.

11.- R. Carter, E.G. Gregorich, Soil Sampling and Methods of Analysis, Second Edition, Taylor \& Francis, 2007.

12.- B.J. Alloway, Heavy Metals in Soils, Blackie Academic \& Professional, 1995.

13.- M. Folchi, in: Departamento de Economía y de Historia Económica, Universidad Autónoma de Barcelona, Spain, 2006.

14.- M. Folchi, in: Simposio de Historia Ambiental Americana, Departamento de Ciencias Históricas, Facultad de Filosofía y Humanidades, Universidad de Chile, Departamento de Ciencias Históricas, Facultad de Filosofía y Humanidades, Universidad de Chile, Chile, 2003.

15.- Giacomino, M. Malandrino, O. Abollino, M. Velayutham, T. Chinnathangavel, E. Mentasti, Environ. Pollut., 158 (2010) 416-423.

16.- G.W. Gee, J.W. Bauder, Particle-size Analysis1, in: A. Klute (Ed.) Methods of Soil Analysis: Part 1-Physical and Mineralogical Methods, Soil Science Society of America, American Society of Agronomy, 1986, pp. 383-411. 